\title{
The Most Popular Fantasy Novel in the Beginning of Twenty- First Century 'Harry Potter'
}

\author{
Osama Farhan Alsharab
}

MA English Language and Literature

\begin{abstract}
Harry Potter is a series written by J. K. Rowling which belongs to the fantasy literature genre. The series contains seven books, the first of which was published in 1997. Each of the Harry Potter stories has an independent plot. The story about an orphan boy. At one year of age, he loses his parents, who are murdered by the dark wizard. This study aims to investigate the factors behind the popularity of Harry Potter by J. K. Rowling as popular culture. To discover the main reasons driving the enormous worldwide popularity of this work, this study offers a literary analysis of Harry Potter by J. K. Rowling as a contemporary fantasy text which has been one of the most famous in the two decades preceding the writing of this paper. The research focusing on the important elements such as settings, characters, plot, themes, and the narrative structure and languag e to figure out factors behind the wide acceptance of Rowling's work. The research findings show that there are many factors behind putting this fantasy text in its position as a pop. culture phenomenon. For example, the elements of the story shaped in such a way to be more attractive. The technological development in the postmodern era also has significant importance within the success of Harry Potter.
\end{abstract}

Keywords-Harry Potter, J. K. Rowling, Popular Culture, Fantasy literature, Fantasy Genre.

\section{INTRODUCTION}

Harry Potter is a series written by J. K. Rowling which belongs to the fantasy literature genre, because magic is present in the course of all of its stories. The series contains seven books, the first of which was published in 1997. These books include Harry Potter and the Philosopher's Stone, Harry Potterand the chamber of secret, Harry Potter and the prisoner of Azkaban, Harry Potter and the Goblet of Fire, Harry Potter and the Order of Phoenix, Harry Potter and the Half-blooded Prince, and the last book published in 2007, Harry Potter and the Deathly Hollows.

The cycle form clearly appears in this work. It takes on the preferred form in the popular culture which is even more common in films. Each story of the cycle shares the main hero. Additionally, the novel is considered as part of the Bildungsroman tradition. The writer employs many Bildungsroman elements such as professors, groups of students as heroes, and the educational environment. In this case, the writer adds fantastic elements in the realistic mode to create a secondary world. Furthermore, the seven books portray the hero's life. For example, in the story, the hero loses his parents. Therefore, he struggles to grow through his experience as an orphan. He searches for his identity and fights to take his place in the life. All of these elements can be characterised as being a part of the Bildungsroman form (Havírová, 2007).

Harry Potter has been one of the world's bestselling books over the last 20 years, and its publisher has sold around 450 million copies until 2011. Rowling's novel has become a global phenomenon. Undoubtedly, the story has had a huge influence on popular culture. Many tactics have been used to attract the readers. For example, different cover illustrations have been used by the publisher to attract both adult and child readers. They have also designed the language of the story to suit a large number of readers. For example, British terms have been changed to American terms (Kidd, 2007).

\section{SUMMARY}

Harry Potter, the protagonist, is an orphan boy. At one year of age, he loses his parents, who are murdered by the dark wizard. At the beginning of the story, Harry is informed that his parents were killed in a car accident. This boy is then brought up in his relatives' house, called the Dursleys, with his cousin who hates him. On his eleventh birthday, a strange creature tells him that he is a wizard. He receives an invitation to attend Hogwarts School of Witchcraft and Wizardry. While attending the school, he starts to learn many things, such as his true heritage and his ability to use magic. He also 
makes many friends, such as Ron Weasley and Hermione Granger. The headmaster of the school, Albus Dumbledore, takes care of Harry Potter and informs him of the actual story about the death of his parents and the evil murderer called Voldemort. After this, he meets the murderer in different forms and faces many dangerous situations.

\section{Plot}

Each of the Harry Potter stories has an independent plot. For example, in the first book, Harry Potter and The Philosopher's Stone, Harryand his friends save the stone at the end of the story, while in the sixth book, Harry Potter and the Half-blooded Price, the story presents the mystery of the half-blood Prince. At the beginning of the series, the villain, Voldemort, is introduced by the writer, and he constantly causes problems and makes the plot more interesting. He is Harry's arch enemy, and he survives each time. Hagrid introduces Voldemort in the first year to Harry in the fourth chapter of Harry Potter and The Philosopher's Stone.

"Nah - can't spell it. All right Voldemort.' Hagrid shuddered. 'Done make me say it again. Anyway, this - this wizard, about twenty years ago now, started lookinfer followers, and got 'em too - some were afraid, some just wanted a bit o'his power. [...] Dark days, Harry. Didn't know who ter trust, didn't dare to get friendly with strange wizard or witches... terrible things happened. He was takin 'over. 'Course, some stood up to him - and he killed 'em. Horribly.'(p. 42)

Through this style, the writer attempts to narrate some details at the beginning of the story that are helpful to both the characters and readers in the revealing of the mystery. For example, in the third story, the author is talking about Ron's rat Scabbers, which is at the end of the story, becomes Harry's enemy. Furthermore, traditional rhetorical device is used by the writer while structuring the plot (for instance, hysteron proteron). By using this device, the reader is provided with information that is significant to explain certain events later during the novel. This device is also used Tolkien's work The Lord of the Rings. Moreover, Rowling uses many elements such as the sensuous moment, suspension, and tension to make the story more attractive. These elements are presented extensively as parts of the characteristics of the protagonist (Havírová, 2007).

\section{Characters}

The charactersin Rowling's literary work follow the same norms in the high fantasy sub-genre. The novel has two groups: major characters and minor characters. Minor characters indicate those without the ability to perform magic. The protagonist Harry as in fantasy fiction, has a magical power that allows him to do supernatural things. Typical to fantasy literature, the main characters or the hero is fighting against evil. In Harry Potter, Harry and his companions represent the good side and Voldemort and his group represent the evil side (Martin, 2009).

The Dark Lord antagonist is Voldemort. The main goal of this character and his army is to convince people to join the dark side and fight with him against good. These characters convey an important message throughout the position and serve as an educational role in the story. It should be noted that the majority of the characters are students, which adds interest to the story. Furthermore, since the plot is designed to delight young readers, the battle between good and evil tend to culminate in the triumph of good. Happy endings make the novels more enjoyable and attractive among children and adolescents (Kidd, 2007).

\section{Settings}

The setting is the most important characteristic in fantasy literature - especially in the sub-genre of high fantasy. The story is often set in the imaginary world. Three types of secondary worlds could be found in high fantasy. First, the writer may create a secondary world with no relationship to the real world, such as in The Lord of the Rings. Second, the writer may use a portal to reach the secondary world, such as in Alice in Wonderland. Third, the writer may place the primary and secondary worlds together. In this case, the writer typically separates the two worlds using a physical boundary such as in The Secrets of the Immortal Nicholas Flamel. In this work, the population in the primary world live with no idea about the events taking place in the secondary world (Gamble, 2013).

As mentioned above, the setting is very important, because it expands the mood of the readers. A curiosity and a sensation of wonder is added to the reader's imagination when a brilliant setting is created. Furthermore, the setting affects the readers more when it can be seen as a real world over the course of the story (Martin, 2009).

In Harry Potter, the primary and secondary worlds co-exist with each other. This appears to be similar to our own reality, and their methods for living do not indicate any dissimilarities with the world of normal 
people, or what we call muggles. For example, it has shops, markets, railroads, and schools - such as Hogwarts School. Despite it being similar to our world, it suffers from a lack of modern devices such as computers or telephones (Jenkins, 2015). Since the muggles in the story do not have a knowledge of the fictional world, Mr. Dursley, as a Muggle, believes that magical behaviour is normal for youngsters. This scene could be found in the first chapter of Harry Potter and the Philosopher's Stone. When it comes to the portal, Rowling uses uncommon portals to take the reader on travels to the parallel world. For example, using floo powder in Harry Potter and the Chamber of Secrets or passing through the stone and tapping the wall in Harry Potter and the Philosopher's Stone. The extract explains that Harry uses the floo powder when he travels to the secondary world in Harry Potter and the Chamber of Secrets.

'Well .... all right ...you go after Arthur, 'said Mrs Weasley. 'Now, when you get into the fire, say where you're going - '

'And keep your elbows tucked in,' Ron advice,

'And your eyes shut, 'said Mrs Weasley. 'The soot - '

'Don't fighter,' said Ron. 'Or you might well fall out of the wrong fireplace - '

'But don't panic and get out too early, wait until you see Fred and George.'

Trying hard bear all this mined, Harry took a pinch of Floo powder and walked to the edge of the fire. He took a deep breath, scattered the powder into the flames and stepped forward; the fire felt like a warm breeze; he opened his mouth and immediately swallowed a lot of hot ash.

'D-Dia -gon Alley,' he coughed.

[...]

And old wooden street sign over a shop selling poisonous candles told him he was in Knockturn Alley. This didn't help, as Harry had never heard of such place (p. 41).

\section{Themes}

The theme in a certain literary work is the central idea that a writer tries to convey it through his/her work. The author uses different literary devices such as plot and characters to create and develop the theme. Examples of themes include betrayal, love, and good vs. evil (James\&Mendlesohn, 2014).

The common theme in Rowling's work is good vs. evil. In Harry Potter, Harry and his companions represent the good side and Voldemort and his group represent the evil side. During the story the two groups are at war, and at the end of the story, good triumphs. This theme tends to be most common in fantasy literature. Moreover, there are many sub-themes which could be found in the series, such as death, love, race, and comingof-age. It should be noted that including many themes within the same work affects a wider audience of readers (Suljic, 2013).

\section{Narrative Structure and Language}

In Harry Potter, the narrative structure follows the norms of high fantasy. In keeping with this, the writer uses quest and voyage. It should also be noted that each story has different structure. For example, in Harry Potter and The Philosopher's Stone, the readers can see both the voyage to Hogwarts and the quest for the stone. By using different structures in the story, the reader feels fresh.

Moreover, the writer utilises language which is appropriate and familiar to young people. This style allows fans to participate in the interaction between characters while reading the story, and they are more easily immersed.

\section{The Important Reasons That Make the Series Appealing}

In fact, Harry Potter is seen as a pop culture phenomenon. Rowling's work highlights several types of fantastic elements, such as strange settings, supernatural characters, and strange creatures. As indicated by Feldt (2016), the best fantasy books are those that are of great importance to their fantasy themes. In this way, fantasy books offer extraordinary and excellent knowledge. Rowling's work is arranged in themes that include enchantments. For example, the story has a coming-ofage theme, which tends to attract teenagers. At the same time, the series also seeks to bring adults back to childhood. Moreover, the events that occur in the story could not happen in reality, but it is similar to our reality in its boundaries between the two worlds. All of these elements affect the readers because Hogwarts, the place where the events of the story are happening, is a world like our own. It contains food, education, and supervision. In this respect, the food serves as a bridge between fans and the characters and reflects culture identity, thus, attracting more readers.

It should be noted that participating in reading novels is perceived as ideal. Reading novels such as Harry Potter allow one to examine what is happening in his/her mind and, as mentioned above, increases his/her reading and vocabulary skills. Many readers are also enthusiastic about the fantasy genre to escape from real 
life. In the last two decades preceding the writing of this paper, Harry Potter has appeared as television movies, realistic books, and computer games. This has made the name of the series even more famous. Furthermore, the technological development in the postmodern era make such stories easy to buy, read, and publish. In using new technology to adapt the series - such as $3 \mathrm{~d}$ effects, camera techniques, and editing - filmmakers create an interesting and amazing expression. These are the main features which earn Harry Potter its popularity in postmodern society.

\section{REFERENCES}

[1] Feldt, L. (2016). Harry Potter and contemporary magic: Fantasy literature, popular culture, and the representation of religion. Journal of Contemporary Religion, 31(1), 101114.

[2] Gamble, N. (2013). Exploring children's literature (3rd ed.). London: SAGE.

[3] Havírová, T. (2007). Fantasy as a Popular Genre in the Works of J. R. R. Tolkien and J. K. Rowling(Unpublished master's thesis). Masaryk University. Retrieved November 25, 2018, from https://is.muni.cz/th/cn231/m.a.pdf

[4] James, E., \& Mendlesohn, F. (2014). The Cambridge companion to fantasy literature. Cambridge: Cambridge University Press.

[5] Jenkins, H. (2015). "Cultural acupuncture": Fan activism and the Harry Potter alliance. In Popular media cultures (pp. 206-229). London: Palgrave Macmillan.

[6] Kidd, D. (2007). Harry Potter and the functions of popular culture. The Journal of Popular Culture, 40(1), 69-89. doi:10.1111/j.1540-5931.2007.00354.x

[7] Martin, P. (2009). A guide to fantasy literature: Thoughts on stories of wonder \& enchantment. Milwaukee, WI: Crickhollow Books.

[8] Rowling, J. K. (2001). Harry Potter and the Philosopher's Stone. London: Bloomsbury.

[9] Rowling, J. K. (2001). Harry Potter and the Philosopher's Stone. London: Bloomsbury.

[10] Suljic, V. (2013). Cross-Culturalism of Harry Potter. Epiphany, 6(1). doi:10.21533/epiphany.v6i1.53 